\title{
Challenges and Opportunities of Higher Education for International Mining Engineers in China: Based on the Practice at Chongqing University
}

\author{
$\mathrm{Li} \mathrm{Liu}^{1,2^{*}}$, Yong $\mathrm{Li}^{1,2}$, Chunhong Ming ${ }^{1,2}$, Gun Huang ${ }^{1,2}$, Zhaolong $\mathrm{Ge}^{1,2}$ \\ ${ }^{1}$ College of Resources and Environmental Science, Chongqing University, Chongqing, China \\ ${ }^{2}$ National Experiment Teaching Center for Virtual Simulation on Mine Mining and Safety, Chongqing University, \\ Chongqing, China
}

\begin{abstract}
Under the background of mineral industry transforms towards global and sustainable development as well as the establishment of innovative country in China, higher requirements for the mineral engineering education have been putting forward. Based on the research on the demands of mining engineers in the domestic and foreign, the mining engineering education objective, which includes the characteristics of international, innovative and interdisciplinary (referred as '3I'), was determined. To achieve the '3I' education objective, the international outlook, the economics and management knowledge, as well as the practical ability for knowledge using were enhanced in the new curriculum. Substantially, a new education system includes three sub-education models was generated. Practical outcomes show that the education system is effective on improving the overall quality of students, especially the innovative ability. In the end, the flaws in learning and teaching in the current education system were discussed, including students' concerns on the global level and understanding different cultures should be strengthened, as well as the teaching contents and teaching philosophy have to satisfy the changes and the demands of the industry development.
\end{abstract}

Keywords: mining engineering, international, innovative, interdisciplinary, education system

\section{Introduction}

A global transformation from an economic towards a sustainable development is promoted by current policies from the countries and unions all over the world (Stock and Kohl 2018). Taking China as an example, the Belt and Road Initiative (B\&R) effort calls for the creation of six economic corridors or areas that would link up to 65 countries by land and sea. These nations represent 60 percent of the world's population and 30 percent of the world's total economic production. The first education summit connected to China's Belt and Road Initiative had taken place in Beijing in 2016. In 2009, Yanzhou Coal Group acquired all the 100\% stake in Felix, Australia. In 2012, it completed the acquisition of Gloucester Coal Company. In 2017, it also acquired the Rio Tinto Coal Company in Australia. In 2011, Shenhua Group and Japan Mitsui products consortium gained $40 \%$ stake in Mongolia Taitorgai coal mine and became the largest shareholder of the project. At present, large mineral enterprises are multinational companies all over the world. There are 6 enterprises have already covered the whole world in the top ten mineral multinational companies. Consequently, young engineers must be trained to anticipate the sustainability challenges for contributing bottom-up to a global sustainable development, as well as be capable of performing in a more and more dynamic, transnational and intercultural global working environment (Li 2013, Yu et al 2013).

Besides the global development of mining industry, the mining technology has a great progress. In China, the number of intelligent unmanned coal mining workplace has reached to 47, and the TBM has been introduced for the construction of long distance inclined shaft in coal mine, as well as the 8.8 meters high support has been developed and came into use, in 2017. For UNESCO, education for sustainable development involves: integrating key sustainable development issues into teaching and learning. This may include, for example, instruction about climate change, disaster risk reduction, biodiversity, and poverty reduction and sustainable consumption. It also requires participatory teaching and learning methods that motivate an empower learners to change their behaviour and take action for sustainable development (UNESCO 2017, Marope et al 2015).

The interdisciplinary development of mining industry is the future of coal. The clear and efficient utilization of coal will receive more attention. According to the International Energy Agency (IEA), the survival and development of coal industry is strongly constrained by clean energy technology. The sub critical coal-fired power generation units with low efficiency will be eliminated immediately, so the development of Carbon Capture and Storage (CCS)

* Corresponding Author: Li Liu, Email: zhliuli@ cqu.edu.cn, phone: +86 2365111468 
technology will become an important protection strategy for coal industry (Oshokoya and Tetteh in Press).

Education must find ways of responding to such challenges, taking into account multiple worldviews and alternative knowledge systems, as well as new frontiers in science and technology such as the advances in neurosciences and the developments in digital technology. Rethinking the purpose of education and the organization of learning has never been more urgent (UNESCO 2015). Consequently, new perspectives for teaching and learning in higher engineering education are required, providing the competencies for coping with the sustainability challenges and for working within the dynamic global society (Wu et al 2014).

\section{Current Situation}

On the one hand, the modernization of coal mines needs a large number of high-quality employees urgently. On the other hand, the brain drain of coal enterprises is serious in recent years. As well as the enrollment of mining engineering in universities is difficult.

The research about coal resources, coal industry policy, laws and regulations, international trade policy of the countries along the $B \& R$, as well as dialogue and communication with the IEA, World Coal Association (WCA) and the coal mining industry need to be strengthened.

According to the survey International Engineering Education of the Students in the College of Resources and Environmental Science in Chongqing University, part of the questionnaire and survey date were shown in Tables 1 and 2, some interesting results are obtained.

The number of valid questionnaire is 244 , within $47.54 \%$ from mining engineering (includes International Accelerated Class), $33.61 \%$ from safety engineering and $17.62 \%$ from environmental science.

$228(93.44 \%)$ students think it is necessary to educate international engineer, while only $20(8.2 \%)$ students pay attention to the discipline internationalization which 14 from mining engineering, 4 and 2 from safety engineering and environmental science, respectively.

$99(40 \%)$ students would like to study abroad after graduating, including 18 students from mining engineering international accelerated class and 33 from mining engineering, account for $47.37 \%$ and $42.31 \%$ of the number of participants of the two classes, and 31 students from safety engineering and 15 students from environmental science. The average ratio is $43.97 \%$ in mining engineering

Table 1 Part of international engineering education questionnaire

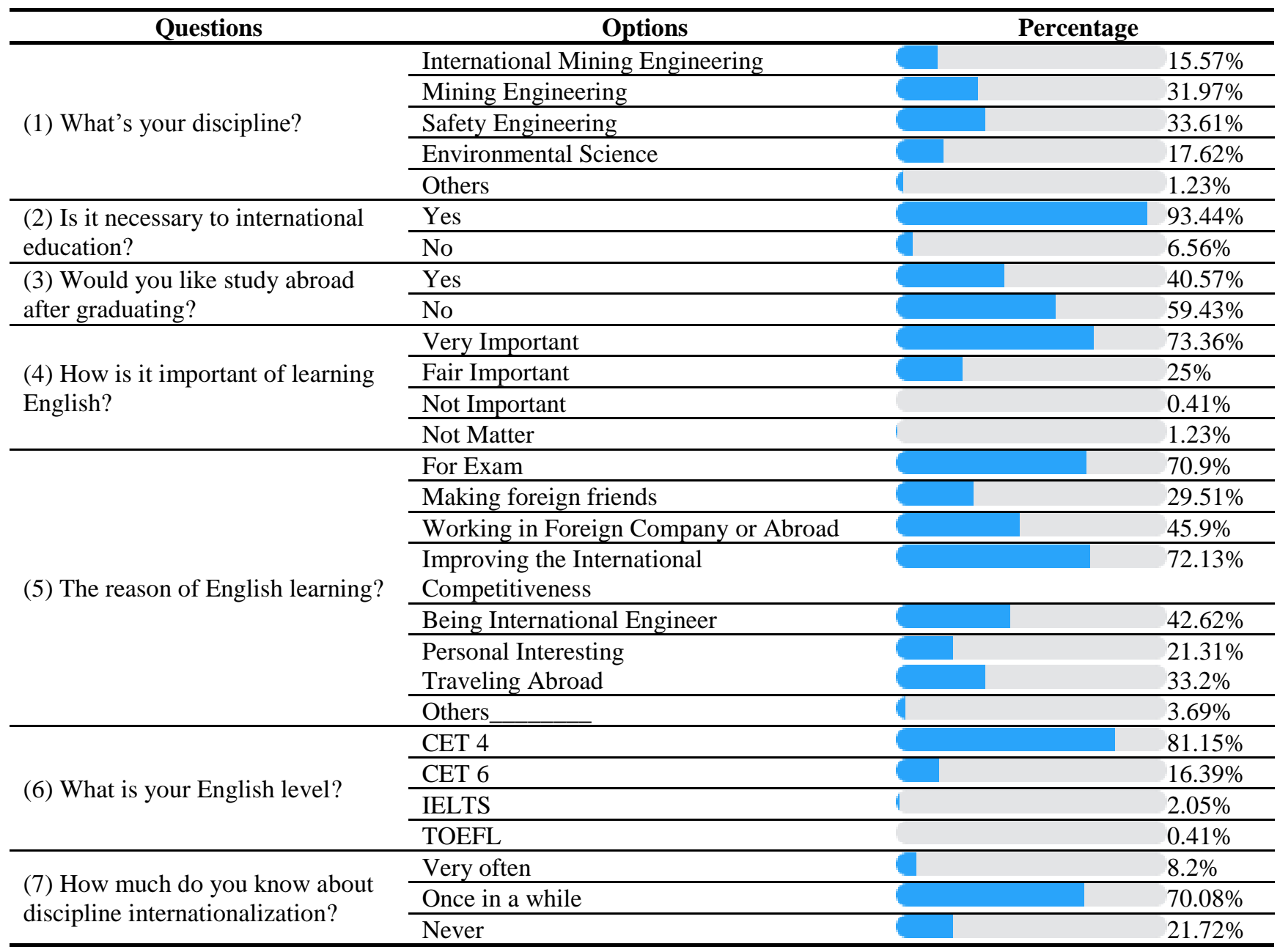


Table 2 Economics and management courses in the mining engineering

\begin{tabular}{cccc}
\hline University & Course name & Credit & Classification \\
\hline \multirow{2}{*}{$\begin{array}{c}\text { Missouri University of } \\
\text { Science and Technology }\end{array}$} & Macro/Micro-economic principles & 3 & Compulsory \\
\cline { 2 - 4 } & Mining economy & 3 & Compulsory \\
\cline { 2 - 4 } The University of \\
Queensland & Mine management & 2 & Compulsory \\
\cline { 2 - 4 } & Professional Practice and the Business Environment & 2 & Compulsory \\
\cline { 2 - 4 } & Engineering Asset Management & 2 & Compulsory \\
\cline { 2 - 4 } & Macro/Micro-economic & 6 & Elective \\
\cline { 2 - 4 } University of Wollongong & Resources assessment & 6 & Clective \\
\cline { 2 - 4 } & Planning and development of mining area & Compulsory \\
\cline { 2 - 4 } & Engineering economy & 3 & Compulsory \\
\cline { 2 - 4 } Mcgill University & Mining economy & 3 & Elective \\
\cline { 2 - 4 } & Mining projects & 3 & Compulsory \\
\hline \multirow{2}{*}{$\begin{array}{c}\text { Clausthal University of } \\
\text { Technology }\end{array}$} & Enterprise management & 3 & Compulsory \\
\cline { 2 - 4 }
\end{tabular}

and $36.8 \%$ in the safety engineering and environmental science. In opinion of the 99 students, the main reason hindering the students study abroad is the economic (90 students chose) and language barrier (41 students chose).

The English skills of the students need to be improved. Only $40(16.39 \%)$ students passed the CET 6, and 5 and 1 student passed IELTS and TOEFL. For mining engineering, the ratio even lower, only $12(10.34 \%)$ and 2 students passed CET 6 and IELTS, respectively.

The first two main reasons for English learning are improving international competitiveness (72.13\%) and passing exams (70.9\%). It shows that students want to improve their abilities, as well as face with heavy exam oriented learning. English learning is driven by both internal and external factors. There is significant correlation $(0.150$, 0.019) between questions 4 and 5.1. It interprets that the main reason why English learning is very important is exam-orientation.

The significant correlation $(0.185,0.004)$ between questions 2 and 3 indicates that the contradictory between the necessary of international engineer education and the desire of study abroad.

The comparison about the curriculum among Chongqing University, Missouri University of Science and Technology, The University of Queensland, Mcgill University, University of Wollongong and Clausthal University of Technology, as shown in Table 2. The most different is economics and management courses.

\section{New Education Framework}

\subsection{Education objective}

Based on the needs of mining industry global development, on the employees demands survey for more than ten international mining enterprises, such as Shenhua Group, Datong Coal Mine Group, Yanzhou Mining Group, Zijin Mining and so on, and the education objectives analysis of mining engineering of University of Queensland, Missouri science and Technology University, Clausthal University of Technology, McGill University and University of Wollongong, a new education objective of mining engineering is proposed after a number of discussions and argumentation of the Alumni Development Advisory Committee, namely International, Innovative and Interdisciplinary engineers, '3I' education objective for short.

\subsection{Curriculum framework}

Based on the outcome-based education (OBE) theory (William 1994), to achieve the '3I' education objective, the imperfections of the current curriculum are obviously. The international outlook, the economics and management knowledge, as well as the practical ability for knowledge using need to be enhanced in the new curriculum (Wang 2013, Felgueiras et al 2017), as shown in Figure 1.

\subsection{Education system}

For coping with the challenges related to global sustainable developments as well as for satisfying the employee demands of the mineral enterprises, new models for teaching and learning in mining engineering education are required.

According to the OBE theory, the education objective of mining engineering education follows the demands of mineral global development and the employee demands of the mineral enterprises (William 1994). For supporting the education objective, the international and interdisciplinary courses, intercultural management and law, as well as innovative practice efficiency throughout the undergraduate curriculum. As a result, a ' $3 I$ ' education system, including mining interdisciplinary innovative education model, teaching model of advanced educational technology integrated into lessons and an international mining education model, was developed, as shown in Figure 2. 


\subsection{Practical Outcomes}

Based on the education model for '3I' engineer education, an International Accelerated Class was established in grade 2013 and grade 2014 for the practice, respectively.

In grade 2013, there are 29 students in total. 2 students have the experience of abroad exchange study in the undergraduate period and 2 students continue their postgraduate study abroad. $12 \quad(41.4 \%)$ students recommended for postgraduate without examination and 8 (27.6\%) students passed the entrance exam for postgraduate. The further education ratio is $75.9 \% .25(86 \%)$ students and $11(38 \%)$ students passed CET 4 and CET 6 respectively.

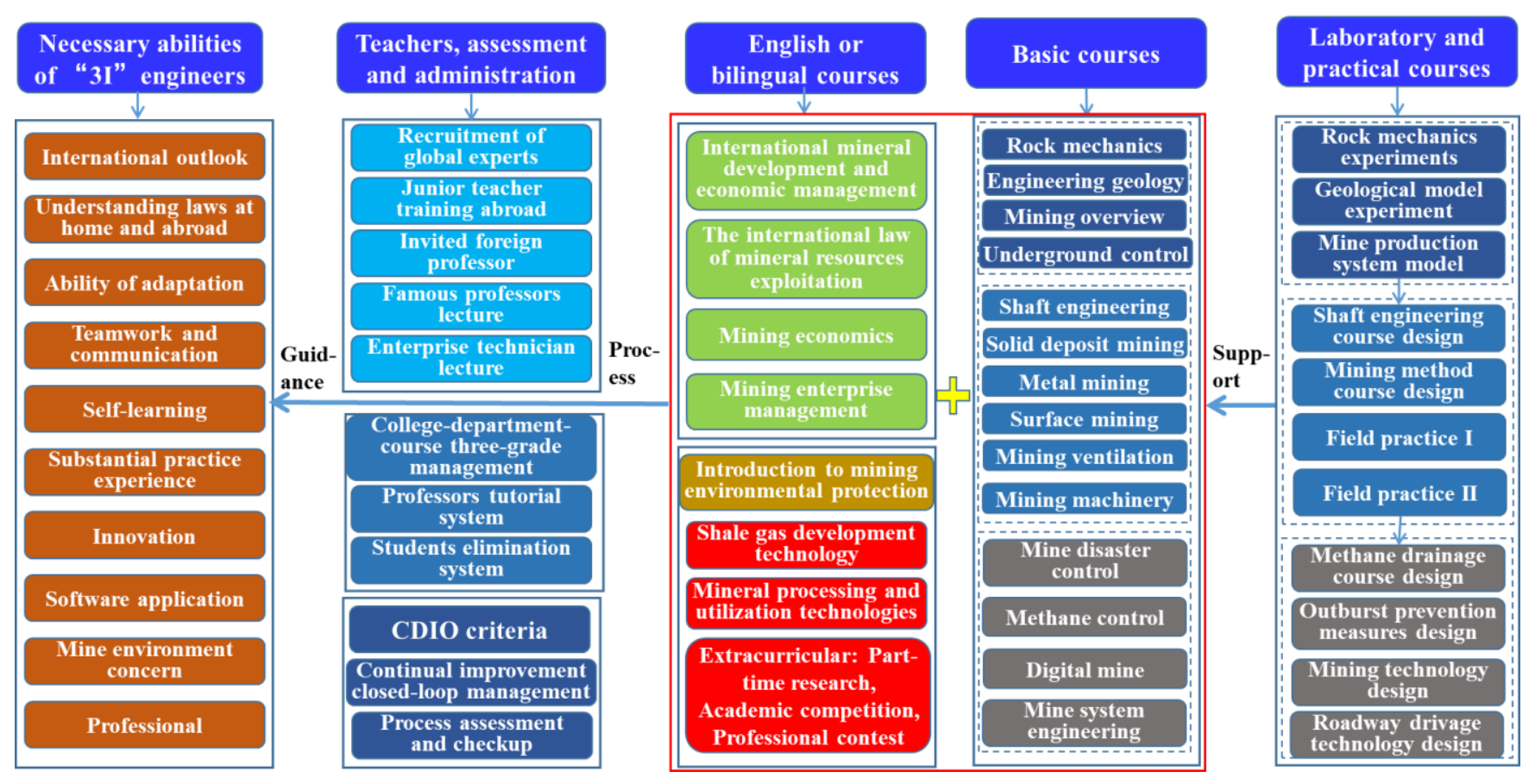

Figure 1 The new curriculum framework

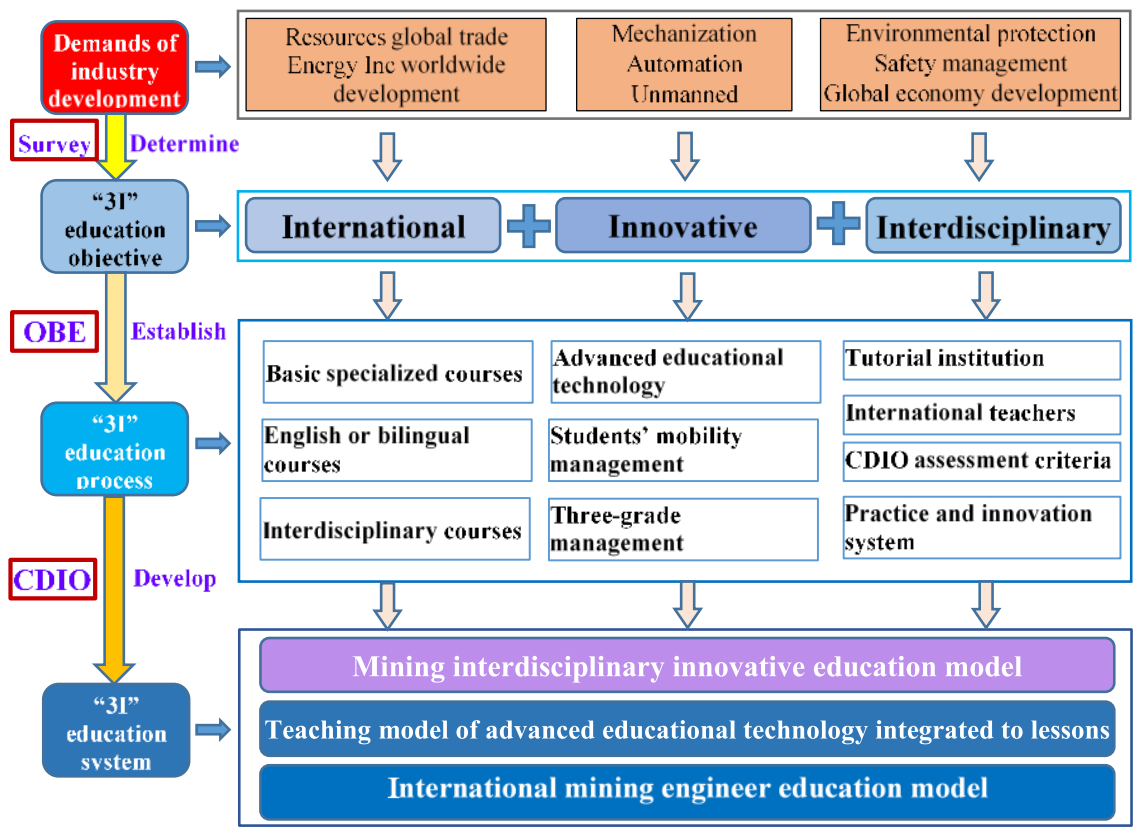

Figure 2 '3I' education system 
In grade 2014, there are 26 students in total. 1 student has the experience of abroad exchange study in the undergraduate period and 3 students will continue their postgraduate study abroad, $10 \quad(38.5 \%)$ students recommended for postgraduate without examination and 4 $(15.4 \%)$ students passed the entrance exam for postgraduate. The further education ratio is $65.4 \%$. $24(92.3 \%)$ students and $10(38.5 \%)$ students passed CET 4 and CET 6 respectively.

According to the '3I' education model, the student' innovation ability have been improved. All the students in International Accelerated Class attended at least one innovation competition, such as The National College Student Innovation Competition (NCSIC), Student Research Training Program (SRTP) and National Higher Education of Mining Engineering Practical Work Contest and so on. Moreover, more than half of the students won the first prize in those competitions.

\section{Summary and Discussion}

The situation of mineral enterprises development and the current mining engineering education were analyzed according to the investigation and survey. A new education objective for mining engineering was proposed. Consequently, a curriculum framework of the transnational, interdisciplinary and innovative for '3I' education objective was established based on the OBE theory. Finally, a new education system includes three sub-education models was generated. The practical outcomes of the new education system were achieved the desire.

The more and more transnational and intercultural working environment coined by global economic trends set new requirements for teaching and learning in mining engineering education. However, there are some flaws in the current education system.

Firstly, the internationalisation of students need to be strengthened. The inadequacies include the language level which concerns to the international communication and understanding of different cultures, the concerns on the industry global development and the knowledge of management and international law.

Subsequently, students' interesting in the discipline is not enough due to mining engineering is an arduous specialty. Studying in the mining engineering is not the first choice of the most of students who are adjusted from another discipline.

In the last, the technology and equipment of mining industry have great progress in the recent years, as well as the teaching methodology and facilities. Consequently, the teaching contents and teaching philosophy have to satisfy the changes and the demands of the industry development.
The '3I' education objective requires teachers to improve their teaching contents and methods.

\section{Acknowledgement}

This research was supported by the Key Research Projects of Higher Education Reform in Chongqing in 2014 (No. 142001) and Research Project on the Reform of Graduate Education and Teaching in Chongqing (No. yjg153007).

\section{References}

Felgueiras, M. C., J. S. Rocha and N. Caetano, 2017. Engineering education towards sustainability. Energy Procedia, 4th International Conference on Energy and Environment Research, 136: 414 - 417.

Li, X.H., 2013. Reflections on the internationalization of Chinese Universities-Practice of international cooperation and exchange in Wuhan University. Journal of World Education, 2: 5 - 10. (in Chinese)

Marope, P.T.M, B. Chakroun and K.P. Holmes, 2015. Unleashing the potential: Transforming technical and vocational education and Training. UNESCO, pp. 9, 23, 25-26.

Oshokoya, P.O. and M.N.M. Tetteh. Mine-of-the-future: How is Africa prepared from a mineral and mining engineering education perspective? Resources Policy, in press.

Stock, T. and H. Kohl, 2018. Perspectives for international engineering education: Sustainable-oriented and transnational teaching and learning. Procedia Manufacturing, 21: 10 - 17.

UNESCO, 2015. Rethinking education: towards a global common good? pp. 9 - 10, 33.

UNESCO, 2017. Education for sustainable development. retrieved 17 Oct 2017.

Wang, J.H., 2013. The idea and strategy of internationalization education of Yale University. Journal of World Education, 3: 37 - 40. (in Chinese)

William, S., 1994. Outcome-based education: Critical issues and answers. Arlington Virginia: American Association of School Administrators.

Wu, H.Y., H.S. Wu, I.S. Chen and H.C. Chen, 2014. Exploring the critical influential factors of creativity for college students: A multiple criteria decision-making approach. Thinking Skills and Creativity, 11(1): 1 - 21.

Yu, L.M., C.T. Yin and H. Chen, 2013. Analysis of higher engineering education development trend and exploration into education internationalization. Research in Higher Education of Engineering, 2: 41 52. (in Chinese) 